\title{
ASPECTS OF SUPPORTING SUBSOIL SOFTENING AT EXCAVATION OF DEEP FOUNDATION PITS
}

Igor Shumakov ${ }^{1}$

Aleksandr Pogrebniak ${ }^{2}$

Oksana Grinchuk ${ }^{3}$

UDK: 69.051:624.131

DOI:10.14415/konferencijaGFS 2016.054

Summary: Evidence from one of the objects in Ukraine with a recessed substructure there were considered aspects of supporting subsoil softening over time. Deformations of differential movement of the foundation pit bottom cause to uneven slumps due to more intensive subsoil softening under the central part of the pit, compared to its edges and corners. Completed laboratory studies of the soil yielded a picture of the soil physical change with stratification depth, and as a result the corresponding characteristic curves were obtained. It was proposed to call the described process and its accompanying phenomena as soil reconsolidation, and the term "reconsolidation factor" was introduced. The authors have proposed the typology of soils, on the base of which the occurrence of the soil softening effect may be predicted.

Keywords: erecting of substructures, pit, soil, foundation, soil softening.

\section{INTRODUCTION}

The contemporary construction practice has actual problem of available ground area utilization. The underground space is used increasingly for building of underground car parks, commercial area etc. And if now such projects are not large-scale, then in prospect usage of deep pits will became usual in building practice, and with that the depth of underground space usage will grow.

In the process of a project completion of the underground space utilization at the pit cutting stage the builders frequently enough face a problem of so-called bottom elevating. Herewith, amount and geometry of elevating are variant and depend of the projected pit depth, its square and geometric form. In the existing literature, a fact of elevating is mentioned without cause analysis and engineering-geological conditions.

\footnotetext{
1 Igor Shumakov, Doctor of Engineering Science, Professor, Managing chair of construction technologies, Kharkov National University of Construction and Architecture, 40 Sumskaya str., Kharkov, Ukraine, tel: +38097 94133 28, e-mail: shumakov.hisi@gmail.com

2 Aleksandr Pogrebniak, Chief Specialist, Ukrainian State Research and Development Institute of engineering and environmental investigations, 38 Nauki ave., Kharkov, Ukraine, tel: +38057 70002 40, e-mail: kstucatbv@ukr.net

${ }^{3}$ Oksana Grinchuk, graduate student, Kharkov National University of Construction and Architecture, 40 Sumskaya str., Kharkov, Ukraine, tel: +38057 70618 54, e-mail: grynchuk-o.a@mail.ru
} 
Contemporary achievements in civil engineering 22. April 2016. Subotica, SERBIA

Basing on the hydraulic structures construction this phenomenon is described by L. Molokov [1, 2]. The most full description of this phenomenon is given in the works of B. Dalmatov [3, 4]. He also proposed the term "soil softening settlement" (which is developing under load don't exceeding natural value, i.e. a load equal to the weight of all the soil excavated during the pit excavation). According to the series of researchers (e.g. B. Dalmatov [3]), during the foundation in the pit less than $5 \mathrm{~m}$ deep, the soil softening doesn't happen or it is insignificant. I.e. it starts from the depth of 5 and mode meters. The other researchers mention the starting softening depth of $8 \mathrm{~m}$. In the basic work [5] this phenomenon also is explained in the section devoted to the swelling soils as one of swelling types connected with "splitting water effect" in the "overconsolidated". In the researches of S. Kozlovskiy and A. Koshelev [6] is mentioned that "...during a pit excavation and common pressure release, a soil softening will happen in the pit bottom at the depth from 2 to $5 \mathrm{~m}$ ". Basing on our researches, this statement is confirmed.

\section{SOFTENING CHARACTERISTICS RESEARCH}

In 2014 the authors performed the engineering-geology research for the projected residential area in Kharkov [7]. In this object an one-level car park was projected with deepening of nearly $5,0 \mathrm{~m}$.

Warkshop examinations was performed for all the engineering-geological elements (EGE). Their results have high convergence of the particular values and was characterized by the normative factors mentioned in the Table 1. After obtaining of the research results, the developer changed the technical parameters of the object, in particular, a 3-level car park was projected with deepening of $12 \mathrm{~m}$.

Pit bead level was projected in the sandy clay bottom (EGE6), with lower sands (EGE 7) with thickness more than $1 \mathrm{~m}$, and lower was heavy sandy clays (EGE 8).

At the 2014 spring the pit excavating was started, which provided to don't reach to the projected pit bottom mark by $1,5 \div 2,0 \mathrm{~m}$. In November 2014 the pit was drawn to the projected mark, and non-correspondence of the pit bottom soils to the examinations materials was realized. Instead of expected sandy clay (EGE 6) and sands beneath them (EGE 7), in the pit central part and at the projected mark a brown sandy clay (EGE 8) was spotted, and the sands (EGE 7) was presented enough at the near-wall pit parts. This demanded additional examinations.

At December 2014 additional examinations have been made at the pit bottom to study the new bottom soils [2]. 3 pores were drilled with depth of $5 \mathrm{~m}$ from the pit bottom, samples of non-ruined structure was taken, a complex of laboratory researches was performed. Furthermore, the soils physical characteristics were compared.

As Table 1 shows, during the period from November till December the consistency (flowability factor) in the soils natural stage didn't changed, and softening want on. The dry soil specific weight from 15,28 lowered down to $14,62 \mathrm{kN} / \mathrm{m}^{3}$. At this time, no strong rains happened, no snow, no frost. Herewith, the following can be concluded. The sandy clays of hard consistency, which will remain hard in water-saturated stage, transformed into semi-hard, and during water saturation became tightly-ductile (November) and further soft-ductile (December). 
Савремена достигнућа у грађевинарству 22. април 2016. Суботица, СРБИЈА

Table 1. Soils physical characteristics change EGE 8 at the different stages of testing

\begin{tabular}{|c|c|c|c|c|c|}
\hline Factors control stages & 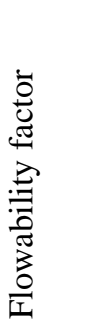 & 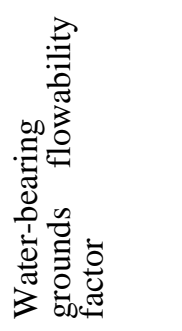 & 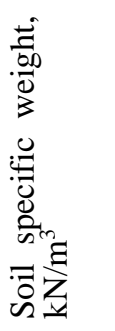 & 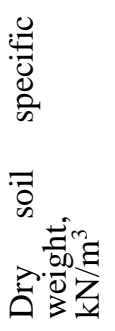 & 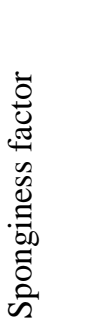 \\
\hline Examinations, 2013 & $-0,18$ & $-0,10$ & 19,91 & 16,58 & 0,61 \\
\hline $\begin{array}{l}\text { Testing from pit, } \\
\text { November } 2014\end{array}$ & 0,19 & 0,28 & 19,04 & 15,28 & 0,76 \\
\hline \multicolumn{3}{|c|}{$\begin{array}{l}\text { Measurement change factor relating examinations } \\
2013\end{array}$} & 0,95 & 0,92 & 1,24 \\
\hline $\begin{array}{l}\text { Pit examinations, } \\
\text { December } 2014 \\
\end{array}$ & 0,19 & 0,57 & 17,95 & 14,62 & 0,83 \\
\hline \multicolumn{3}{|c|}{ Change factor relating examinations 2013} & 1,11 & 1,13 & 1,36 \\
\hline \multicolumn{3}{|c|}{ Change factor relating examinations 2014} & 0,94 & 0,95 & 1,09 \\
\hline
\end{tabular}

Moreover, the soils physical factors change with depth was examined. The data is mentioned in the graphs form at the Figures 1-3. Straight line is normative factor value during the 2013 examinations. Polylines are the values by three pores (1, 2, 3- number of pores).

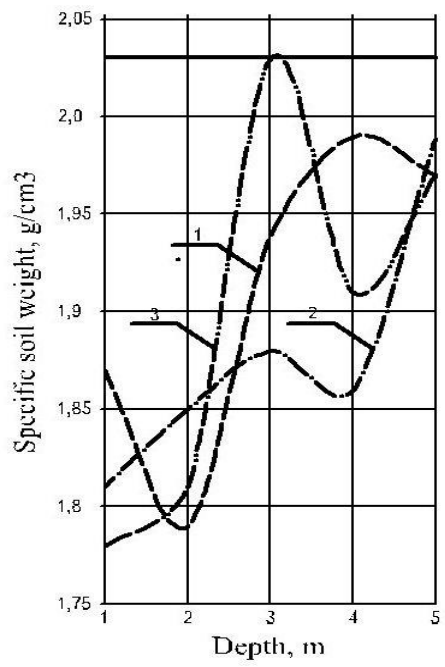

Figure 1. Specific soil weight change with depth 
Contemporary achievements in civil engineering 22. April 2016. Subotica, SERBIA

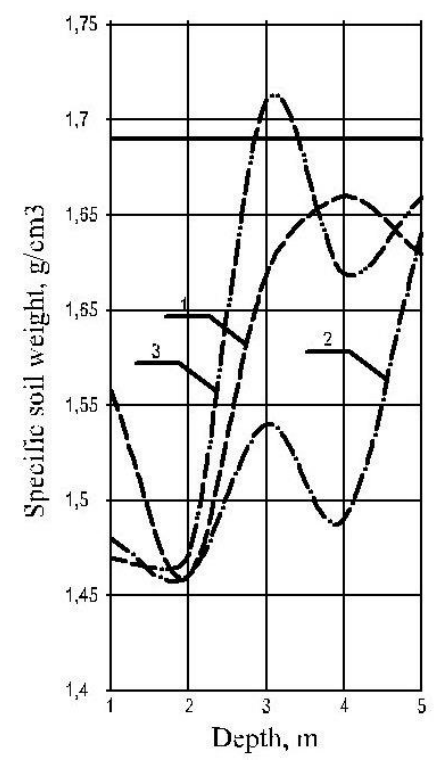

Figure 2. Specific dry soil weight change with depth

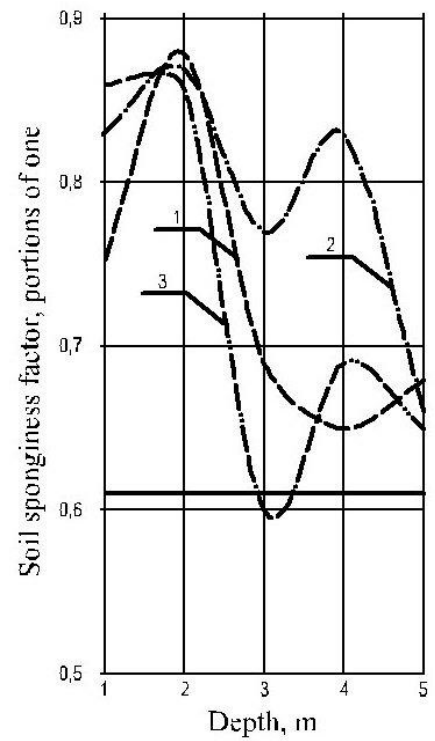

Figure 3. Soil sponginess factor change with depth

In the result of softening and connected with this soil volume growth at the near-wall part of the pit, the bead lifted at the height of $0.5 \mathrm{~m}$, and at the height of $1.5 \mathrm{~m}$ at the central part. 
The obtained relationships analysis permits to talk about pronounced tendency: maximum soil softening happened down to $2 \mathrm{~m}$ from the pit surface, and further at the depth of $5 \mathrm{~m}$ the approach of the examined factors to the normative values is observed. Herewith, we mention immediately that changed thickness is about $5 \mathrm{~m}$, and deeper grounds properties remained similar to the normative characteristics of the 2013 examinations.

As the mentioned data shows, the geotechnical conditions of the site were changed significantly. The physical-mechanical properties change of soils was happened in the direction of their degradation and, as a result, additional resources were needed for building at this site. This demanded a scientific-technical estimate. Swelling? No: those soils were examined for swelling properties. Is this a known process of the pit bottom lifting due to the hydrostatic pressure release? No. Underground waters at this site are occurs deeper than $26 \mathrm{~m}$ from the surface and virtually have no pressure. The authors reached a conclusion that this soil softening occurred due to the common pressure release. "Water propping factor" is likely the mechanism of this phenomena is definitely true. The softening thickness layer is no more than $5 \mathrm{~m}$ during pits excavating of 10 $15 \mathrm{~m}$ depth.

We can fit it to the group of swelling only provisionally, due to the lack of another established approach. The difference is significant. During the swelling processes, a water gets into the soil structure, which leads tits volume growth. During the softening all happens vice versa. In the first hand the porosity grows, then the soil will be ready to receive additional moisture. Moisture capacity is the secondary process.

In its natural occurrence, overconsolidated sandy clays are water tight and cannot receive the water in their structure. The problem begins solely after release of the above laying soils natural weight - common pressure. Only after that the specific soils began to represent their special properties.

The authors propose to call the described process and its following "soils reconsolidation". According to the authors opinion, it is more correctly to use a term reconsolidation factor $\left(K_{\text {rec }}\right)$ instead of the term "reconsolidation settlement" by D. Dalmatov. The cause is that during the reconsolidation process the "softening settlement" is not equal to the "consolidation settlement" taking into account of the time factor. Lifetime of any structure is incommensurable with the geological time during which an initial dynamic balance formed (consolidation happened), and in means that if the soils will be loaded evenly with equal starting technogenic load, then after the normative time of the structure existence the soils will not reach initial density.

The reconsolidation process begins under the dynamic balance disequilibrium of the system "pore pressure - common pressure". At the same time the reconsolidation factor depends on the soil physical factors $(A)$, the released common pressure value $\left(P_{\text {com }}\right)$ and the softening time $(t)$, which is confirmed by the data quoted in the Table 1 .

$$
K_{\text {rec }}=f\left(A, P_{\text {com }}, t\right)
$$

Taing into account that every specific case during the pit excavating in the specific place and for known depth $(A)$ and $\left(P_{\text {com }}\right)=$ const, we obtain that the reconsolidation factor is a time function $f(t)$. Thereby, from the reconsolidation beginning moment (the system's dynamic balance violation) it will last either till the moment of acquisition by the system 
Contemporary achievements in civil engineering 22. April 2016. Subotica, SERBIA

of the new balance factors, or till the reconsolidation balancing by the building structures weight (with the back filling weight).

But herewith the deformation properties will differ (significantly in certain cases) from the starting depending of the reconsolidation stage. Also the strength properties will differ. By the existing data, the specific adhesion will change significantly, and the internal friction angle will not change.

So, if during the deep pit excavating the technology norms and the normative documents on the order and terms of the pit development are observed, then rarely before the beginning of the foundation bed concrete casting, the negative phenomena will have no time to occur. But it isn't mean that they will not emerge during the building construction and use. From the other side, it is possible that no lifting will occur.

Having the equal pit depth, Min one case the lifting occurs, and in the other it will be not significant, and in the third it will be missing. I.e., the pit bottom lifting is an outside sign of the reconsolidation of the foundation base soils or the soils in the foundation active zone.

The authors propose the following soils typification that support or not support softening.

1. The sites where the reconsolidation consequences can not to be taken into account during the deep pits projecting:

- rock and semi-rock formations;

- sand and big-fragmented soils;

- stabilized soils.

2. The sites where the bead soils reconsolidation will or can occur during projecting and excavating of deep pits:

- cohesive soils (without cementing ties) at the pit bottom or in the softening zone.

During the engineering-geological examinations, for the project development considering a deep pit, the examining organization task may include also determination of the potential danger of soils reconsolidation in the foundation footprint.

\section{CONCLUSIONS}

During the pit excavating, as a result of the soil removal (common pressure release), a bottom soils softening occurs. Moreover, under the pressure of the soil placed along the pit perimeter, the deformations are developed, which leads to the pit bottom uneven lifting, and further to the uneven soil settlement due to the higher soil softening under the pit center rather than along perimeter. The maximum stresses occurs at the near-bottom walls part and, especially, pit corners.

The bottom soils softening cause is the common pressure release, which violate dynamic balance of the soil massive, the balance between the soil pore pressure and the overlying soil pressure. The sedimentation processes during the geological time formed a complicated, dynamically equal system, in what the soils lost certain quantity of the inner pore moisture, depending of weight of overlying soils (common pressure), developed maximum possible dense structure with known soil particles dimension. If it hasn't gave the soil skeleton cementation, which has cementation ties force stronger than the pore pressure - we obtain potentially dangerous soils with their softening possibility. 
As far as these soils forming occurred from the deposit formation period and till the present time in certain conditions, which led to their natural consolidation, then the technical factor intervention (of a natural - erosion for instance) will led to the natural consolidation change.

\section{EXAMINATIONS PROSPECTS}

Taking into account the relevance and complexity of this topic, the first-hand and middle-term tasks must include the following:

- soils reconsolidation process modeling in the workshop conditions;

- reconsolidation parameters determination for different soils types under the different variables;

- determination of the compressibility parameters and strength characteristics after full and partial reconsolidation;

- loads determination that stop the started reconsolidation during the different stages;

- reconsolidation staging determination.

\section{REFERENCES}

[1] Molokov, L.: Engineering-geological Processes, Nedra, Moscow, 1985.

[2] Molokov, L.: Engineering constructions interaction with the geological environment, Nedra, Moscow, 1988.

[3] Dalmatov, B.: Soils mechanics, bottoms and foundations, Stroiizdat, Leningrad, 1988.

[4] Dalmatov, B.: Calculation of buildings and constructions bases by limiting states, Building literature publishers, Leningrad, 1968.

[5] Soil Science, under edition of V. Trofimov, Moscow, Nauka, 2005.

[6] Kozlovskiy, S., Koshelev, A.: Validity of the soils deformation ability determination by the field research techniques. Technology, machinery, equipment, materials for civil engineering : Proceedings of the International Scientific Conference 25-27 $7^{\text {th }}$ of January, Moskow, 2007.

[7] Scientific-technology report about the engineering-geological examinations for cnstruction of the residential area with the social and engineering infrastructure objects at the address: Kharkov city, Moskovskiy ave. (between the 12th of April and the Second Five-Years Plan), archive of HG IGO GP "UkrNIINTIZ", Kharkov, 2014. 